\title{
A Framework for Quality of Service Support in Things-as-a-Service Oriented Architectures
}

\author{
E. Mingozzi, G. Tanganelli and C. Vallati \\ Dip. Ingegneria dell'Informazione, University of Pisa, L.go L. Lazzarino \\ 1, I-56122, Pisa, Italy
}

Received 28 May 2014; Accepted 28 June 2014

Publication 31 August 2014

\begin{abstract}
M2M applications allow the secure and dependable automation of tasks to improve industrial productivity and quality of life of citizens. Task automation is realized by a closed loop between data sensing and actuation, and implemented by means of a large number of smart objects pervasively deployed in the physical world, and control logic running at the core of the M2M application. In critical scenarios, however, such as public safety systems or personal health-care, the control is only effective if it is able to operate while meeting specific real-time requirements. In this work we present a general solution to support the broad range of QoS requirements that characterize heterogeneous M2M applications. The proposed solution is designed with particular attention to scalability and reliability in order to be integrated into large IoT deployments, and comprises a QoS model and a framework for QoS negotiation and resource allocation. The framework has been included in the runtime platform for M2M applications developed by the EU-FP7 project BETaaS: Building the Environment for the Things as a Service.
\end{abstract}

Keywords: Quality of Service; M2M applications; Internet of Things; Service Level Agreement; SLA Negotiation.

Journal of Communication, Navigation, Sensing and Services, Vol. 1, 105-128.

doi: 10.13052/jconasense2246-2120.121

(C) 2014 River Publishers. All rights reserved. 